\title{
INTERNATIONAL JOURNAL OF AUTOMOTIVE SCIENCE AND TECHNOLOGY
}

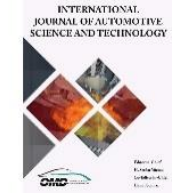

\section{Performance Comparison of Propylene Glycol-Water and Ethylene Glycol-Water Mixtures as Engine Coolants in a Flat-Tube Automobile Radiator}

\author{
Ahmet Gündem ${ }^{1}$, Murat Hoşöz ${ }^{1 *}$, Erkan Keklik², \\ 0000-0001-8129-1302 ${ }^{1}, 0000-0002-3136-9586^{1 *}, 0000-0002-8297-046 X^{2}$
}

${ }^{1}$ Department of Automotive Engineering, Kocaeli University, Kocaeli, 41001, Turkey

${ }^{2}$ BURSAMAK San. ve Tic. Ltd. Şti., Nilüfer-Bursa, Turkey

\section{Abstract}

This study aims at evaluating and comparing the thermal performance of five different engine coolants employed in an experimental engine cooling system with a flat-tube louvered-fin automobile radiator. For this purpose, a PLC-controlled test system was set up. The system could maintain the temperatures of the air and coolant at the radiator inlet, the speed of the air and flow rate of the coolant at the required values during the tests. The tested coolants were pure water, 30/70 ethylene glycol (EG)/water, 30/70 propylene glycol (PG)/water, 50/50 EG/water and 50/50 PG/water mixtures. In all tests, the coolant temperature at the radiator inlet was kept at $90^{\circ} \mathrm{C}$, while the coolant flow rate was varied between $0.10-0.25 \mathrm{l} / \mathrm{s}$ with $0.05 \mathrm{l} / \mathrm{s}$ increments. Furthermore, the air temperature at the radiator inlet was kept at 25,30 and $35^{\circ} \mathrm{C}$, and the air speed passing over the radiator was varied between $1-4 \mathrm{~m} / \mathrm{s}$ with $1 \mathrm{~m} / \mathrm{s}$ increments. The thermal performance of the radiator was evaluated by locating the measured coolant flow rate and coolant inlet/outlet temperatures into the conservation of energy equation. It was found that water yielded the highest radiator heat rejection rates. Compared with water, 30/70 EG/water, 50/50 EG/water, 30/70 PG/water, $50 / 50 \mathrm{PG} /$ water mixtures yielded on average $3.50 \%, 7.89 \%, 8.28 \%, 11.46 \%$ lower radiator heat rejection rates, respectively. Since PG has some advantages over EG such as lower cost and toxicity, PG mixtures can be employed as antifreeze instead of EG mixtures in expense of a slight decrease in the thermal performance.

Keywords: Automobile; Coolant; Engine cooling; Ethylene glycol; Propylene glycol
Research Article

https://doi.org/10.30939/ijastech..914901

$\begin{array}{ll}\text { Received } & 12.04 .2021 \\ \text { Revised } & 09.05 .2021 \\ \text { Accepted } & 17.05 .2021\end{array}$

* Corresponding author

Murat Hoşöz

mhosoz@kocaeli.edu.tr

Address: Department of Automotive Engineering, Faculty of Technology, Kocaeli University, Kocaeli, Turkey

Tel: +902623032279

\section{Introduction}

When the chemical energy of the fuel is converted into mechanical energy in internal combustion engines, some portion of the fuel energy is rejected into the ambient air, which is about $30 \%$ in spark ignition engines and 21-26\% in diesel engines [1]. If aluminum alloys and cast-iron alloys, common materials used for manufacturing engine blocks, are exposed to temperatures exceeding $300{ }^{\circ} \mathrm{C}$ and $400{ }^{\circ} \mathrm{C}$, respectively, distortion and fatigue cracks may occur due to thermal stresses [2]. Moreover, the cylinder wall temperature should be kept below approximately $65^{\circ} \mathrm{C}$ to prevent the evaporation of the lubricating oil [1]. Otherwise, excessive wear caused by insufficient lubrication may lead to serious engine damage. On the other hand, if the engine is overcooled, the fuel will not evaporate properly, and some portion of the exhaust gases will condense on the cylinder walls. Consequently, the engine power and thermal efficiency will decrease while unwanted exhaust emissions will increase.

Due to the limited space in vehicles, it is desired that the radiator dimensions remain within certain limits. Therefore, the engine cooling system should have high performance to reject the unwanted heat within an allowable radiator volume. Furthermore, the engine cooling system should be light enough to cause an acceptable increase in the total weight of the vehicle. So far, manufacturers have managed to enhance the radiator performance considerably by improving their designs. Another way to increase the heat rejection rate in a radiator is to use a coolant with a high thermal performance [3], which necessitates a high thermal conductivity for the coolant. Furthermore, the coolant has a low viscosity to be circulated through the system with a low pumping power [4]. Presently, water and glycol mixtures are employed in engine cooling systems to reduce the freezing temperature of the coolant. However, the thermal conductivity of glycol mixtures is less than water. Although ethylene glycol (EG) is widely used as antifreeze in engine cooling system, propylene glycol (PG) may be an alternative to EG because it has less toxicity, easy to produce, cheap and easily decomposable in nature [5]. Unfortunately, there have been few studies on the comparison of the thermal performance of PG and EG as engine coolant in the literature. 
Sahoo et al. investigated the energetic and exergetic performance of flat-tube rectangular-fin car radiator using water, EG, PG and their brines [5]. They found that 25\% PG-water mixture showed about the same energetic and exergetic performance with water and a better cooling performance than $25 \%$ EG-water mixture. Gollin and Bjork compared the thermal performance of six coolants, namely water, pure PG and their two mixtures as well as two EG-water mixtures, in automobile radiators [6]. They determined that the coolant with the highest thermal performance was water, which was followed by 50/50 EG/water, 50/50 PG/water, 70/30 EG/water, 70/30 PG/water, and eventually PG in decreasing order. Soylu et al. experimentally and theoretically studied the effects of four different types of nanofluids on the thermal performance of an automobile radiator [7]. They prepared the nanofluids by adding different proportions of pure $\mathrm{TiO}_{2}, \mathrm{TiO}_{2}$-blended with $0.1 \% \mathrm{Ag}, \mathrm{TiO}_{2}$-blended with $0.3 \% \mathrm{Ag}$, and $\mathrm{TiO}_{2}$-blended with $0.1 \% \mathrm{Cu}$ into a $50 / 50 \mathrm{EG} /$ water mixture. They determined that $0.3 \%$ Ag-blended nanofluids had the highest thermal conductivity and blending with Ag increased the heat transfer properties of the nanoparticles. Kumar et al. examined the thermo-fluid performance of 60/40 EG/water containing various proportions of nanoparticles in an automobile radiator with louvered fins [8]. They observed that when $2 \%$ aluminum oxide, copper oxide and zinc oxide were added to the based coolant, the heat transfer coefficient of the coolant increased by $42.5 \%, 47.5 \%$ and $51.1 \%$, respectively. Rai et al. studied the thermal performance of an automobile radiator using a distilled water/EG base coolant containing magnesium oxide nanoparticles under various test conditions [9]. Their results showed that the heat transfer rate enhanced when the nanoparticle concentration was increased. Junior and Nogueira theoretically investigated the effects of various coolants containing water, 50\% EG and silver nanoparticle aqueous solution on the performance of an automobile radiator [10]. They found that the use of nanoparticles and EG improved the thermal performance of the radiator. Sahoo et al. investigated the energetic and exergetic performance of an engine cooling system using water, EG, PG, mixtures of EG and PG with water, nanofluid added water and sugarcane juice as coolant and employing a louvered-fin automobile radiator [11]. They found that sugarcane juice yielded slightly better performance than water and nanofluid added water in terms of pumping power and heat transfer, and quite better performance than EG and PG. Habibian et. al. modeled the thermal performance of car radiators with louvered, triangular vortex generator and rectangular vortex generator fins and compared their performance with that of plainfin radiators [12]. In addition, they investigated the effects of adding copper oxide and aluminum oxide particles in different volume ratios to EG on the thermal performance of the radiator with louvered and rectangular vortex generator fins. They found that the heat transfer rate decreased with the addition of EG, increased with the addition of nanoparticles, and the louvered fin had the best thermal performance relative to other fin types. Scoot and Weir examined the performance of engine cooling systems of heavy-duty vehicles using PG and EG coolants [13]. They found that the seal life of two different types of water pumps using PG was longer than that of EG, and that thermostats and radiators performed identically on both glycols. Juger and Crook tested 50/50 PG/water and $50 / 50 \mathrm{EG} /$ water mixtures as coolant in the radiators of heavy-duty vehicles with different geometries [14]. They found that the thermal performance of PG was poorer than EG and that the thermal performance of 50/50 $\mathrm{PG} /$ water mixture at high flow rates was considerably poorer than 50/50 EG/water and pure water. Greaney et al. compared the performance of PG and EG coolants in a real vehicle test performed at low temperature conditions [15]. They did not observe any measurable performance difference between the PG and EG coolants below $-40^{\circ} \mathrm{C}$. Greaney and Cozzone tested PG-water mixtures as engine coolant in heavy-duty vehicles and automobiles and compared their performance with EG mixtures [16]. They determined that PG was a very good coolant for modern engine cooling systems providing the necessary heat transfer properties as well as freezing, boiling and corrosion protection. Tijani and Sudirman evaluated the thermal performance of nanofluids obtained by adding $\mathrm{Al}_{2} \mathrm{O}_{3}$ and $\mathrm{CuO}$ nanoparticles with a concentration of $0.05 \%, 0.15 \%$ and $0.3 \%$ into the $50 / 50 \mathrm{EG} /$ water mixture in an automobile radiator [17]. They found that the nanofluid containing $\mathrm{CuO}$ particles showed the best thermal performance. Goudarzi and Jamali evaluated the effects of wire coil and EG-based $\mathrm{Al}_{2} \mathrm{O}_{3}$ nanofluid on the thermal performance of an automotive radiator [18]. They found that the use of wire coil increased the heat transfer rate by about $9 \%$ and that using different concentrations of nanofluids together with the wire coil caused an additional 5\% increase in the heat transfer. Elsaid experimentally investigated the thermal performance of an automobile radiator in hot climate conditions [19]. Moreover, he added aluminum oxide and cobalt oxide nanoparticles to 10/90 and 20/80 EG/water mixtures and pure water. He found that the thermal performance of cobalt oxide nanofluid was greater than aluminum oxide nanofluid and that the addition of EG reduced the Nusselt number. Ahmed et al. experimentally studied the thermal performance of an automobile radiator using $\mathrm{TiO}_{2}$-water nanofluid as a coolant [20]. They determined that nanofluid with $0.2 \% \mathrm{TiO}_{2}$ concentration could increase the effectiveness of the radiator by $47 \%$ compared to nanofluids with 0.1 and $0.3 \% \mathrm{TiO}_{2}$ concentration and pure water. Zhou et al. obtained different nanofluids by adding $\gamma-\mathrm{Al}_{2} \mathrm{O}_{3}, \alpha-\mathrm{Al}_{2} \mathrm{O}_{3}$ and $\mathrm{ZnO}$ nanoparticles to PG coolant [21]. They investigated the effects of nanoparticle size and type, volumetric concentration, inlet temperature and flow rate of the nanofluid on the thermal performance. They found that the heat transfer coefficients first increased, and then decreased with the increase in volumetric concentrations of all nanofluids. Salamon et al. experimentally examined the thermal performance of a 70/30 water/PG-based nanofluid with $0.1 \%$ and $0.2 \% \mathrm{TiO}_{2}$ concentration in an automobile radiator and compared it with the performance of water and water/PG mixtures [22]. They found that the heat rejection rate obtained with PG was higher than that yielded by the nanofluid at low coolant inlet temperatures. Jagadishwar and Babu experimentally investigated the thermal performance of $\mathrm{TiO}_{2}$ nanofluid with water/PG-based fluid in an automobile radiator [23]. They found that the heat transfer rate increased with the increase in the $\mathrm{TiO}_{2}$ concentration and 
the volumetric flow rate of the coolant. Elsebay et al. numerically investigated the thermal and flow performance of a flat-tube automobile radiator by using $\mathrm{Al}_{2} \mathrm{O}_{3}$ /water and $\mathrm{CuO}$ /water nanofluids [24]. They found that the thermal performance of the radiator was much better with the use of nanofluids. Ali et al. experimentally investigated the effects of nanofluids with four different $\mathrm{ZnO}$ concentrations and pure water on the thermal performance of an automobile radiator [25]. They found that when the coolant inlet temperature increased from $45^{\circ} \mathrm{C}$ to $55^{\circ} \mathrm{C}$, the heat transfer rate enhanced by $4 \%$. They also found that the coolant containing $0.2 \%$ $\mathrm{ZnO}$ rejected $46 \%$ more heat than water. Ramalingam et al. investigated the thermal performance of nanofluids containing different sizes of silicon carbide in an automobile radiator [26]. They found that the $24 \mathrm{~nm}$ small particles showed higher thermal performance than the $110 \mathrm{~nm}$ large particles.

In this study, a PLC-controlled radiator test system has been developed to test the thermal performance of automotive radiators. A flat-tube louvered-fin radiator was used as the test radiator, and the performance of five different engine coolants were tested, namely pure water, 30/70 EG/water, 30/70 PG/water, 50/50 EG/water and $50 / 50 \mathrm{PG} /$ water mixtures. During the tests, the temperature of the air entering the radiator, the speed of the air passing over the radiator and the flow rate of the coolant were changed, and the thermal performance of the radiator was evaluated for a fixed coolant inlet temperature for all coolants. The results were presented comparatively as functions of the test conditions.

\section{Material and Method}

This investigation proposes evaluating comparative thermal performance of a flat-tube louvered-fin automobile radiator using various engine coolants. The tests were performed in a PLCcontrolled radiator test system. It consists of the test radiator, an air resistance to maintain the desired air temperature at the radiator inlet, a coolant resistance to provide the desired coolant temperature at the radiator inlet, subsystems in which air flow and coolant circulation occur, electric motors of the fan and pump, drivers of the electric motors and air/coolant resistances, various measuring instruments, drivers of these instruments and the PLC control panel operating the drivers to provide the desired test conditions. The schematic drawing of the radiator test system is shown in Fig. 1, and its photograph is indicated in Fig. 2.

The system through which the coolant is circulated has a stainless-steel coolant tank, coolant resistor, centrifugal pump, and the automobile radiator. The centrifugal pump is operated by a driver connected to the PLC to ensure the circulation of the coolant within the system at the desired volumetric flow rate. There are two coolant heating resistances located in the coolant tank. These coolant resistances, each having a heating capacity of $7.5 \mathrm{~kW}$, are energized by a driver connected to the PLC to keep the radiator inlet temperature of the coolant at the desired value. The air flow system consists of an axial fan, air resistance, a free fan providing a uniform air flow and a flow straightener. The rotational speed of the axial fan can be varied by the PLC to obtain the desired air speed across the radiator. For this purpose, the $550 \mathrm{~W}$ three-phase AC motor of the axial fan is energized by the PLC via the driver. Furthermore, to maintain the radiator inlet temperature of the air at the desired value, the air resistance is energized by the PLC via the driver, which can vary the capacity of the air resistance between 0 and $10 \mathrm{~kW}$.

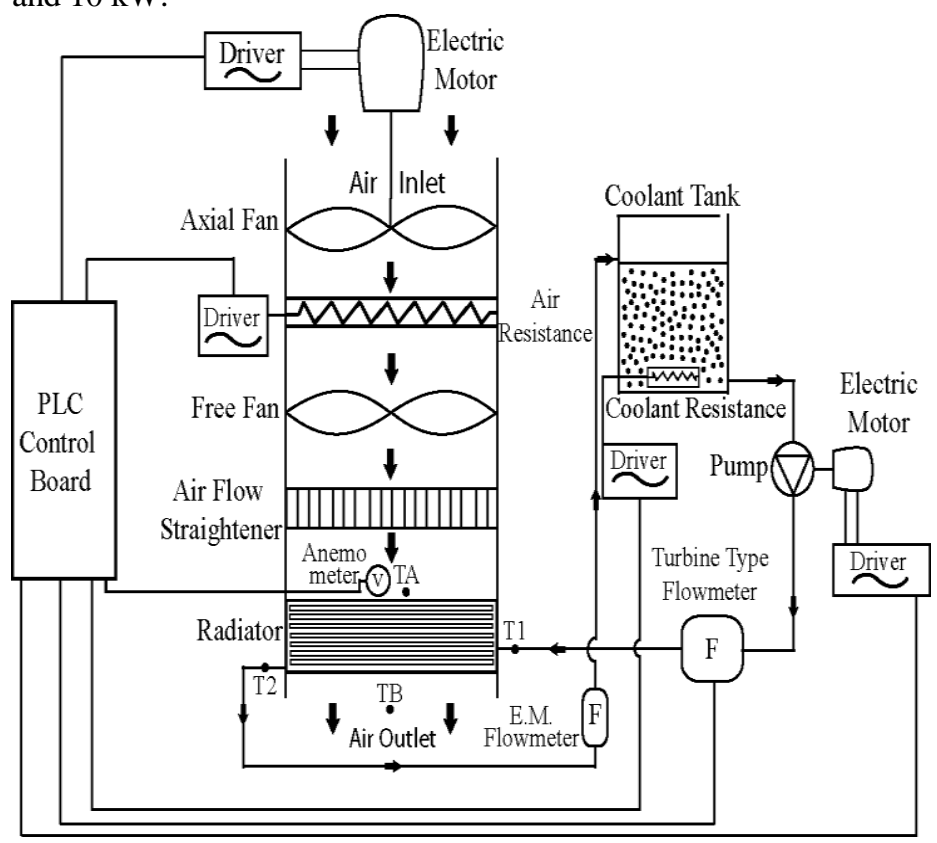

Fig. 1. Schematic drawing of the radiator test system

Table 1. Characteristics of the instruments

\begin{tabular}{c|c|c|c}
\hline Measured parameter & Instrument & Range & Accuracy \\
\hline Coolant flow rate & $\begin{array}{c}\text { Turbine Type } \\
\text { Flowmeter }\end{array}$ & $0-6 \mathrm{~m}^{3} / \mathrm{h}$ & $\pm 1 \%$ \\
\hline Temperature & $\begin{array}{c}\text { J-type } \\
\text { Thermocouple }\end{array}$ & $0-400^{\circ} \mathrm{C}$ & $\pm 2.2^{\circ} \mathrm{C}$ \\
\hline Air Speed & $\begin{array}{c}\text { Velocity } \\
\text { Transmitter }\end{array}$ & $0-20 \mathrm{~m} / \mathrm{s}$ & $<0.2 \mathrm{~m} / \mathrm{s}$ \\
\hline
\end{tabular}

In addition to the instruments employed in the system, some instruments were used to check and calibrate them as well as the PLC. The T symbols in Fig. 1 denote the points at which air and coolant temperature measurements were conducted. All temperatures were measured by J-type thermocouples, and their values were indicated on the PLC screen. The air velocity was measured upstream of the radiator by a velocity transmitter, and its value was shown on the PLC screen as well. This measured velocity was cross-checked by a vane-anemometer, and the transmitter was calibrated accordingly. The coolant volume flow rate was measured by a turbine type flow meter, and its value was indicated on the PLC screen. This flow rate was cross-checked by an electromagnetic flow meter installed in series with the turbine type flow meter, and the turbine flow meter was calibrated accordingly. 


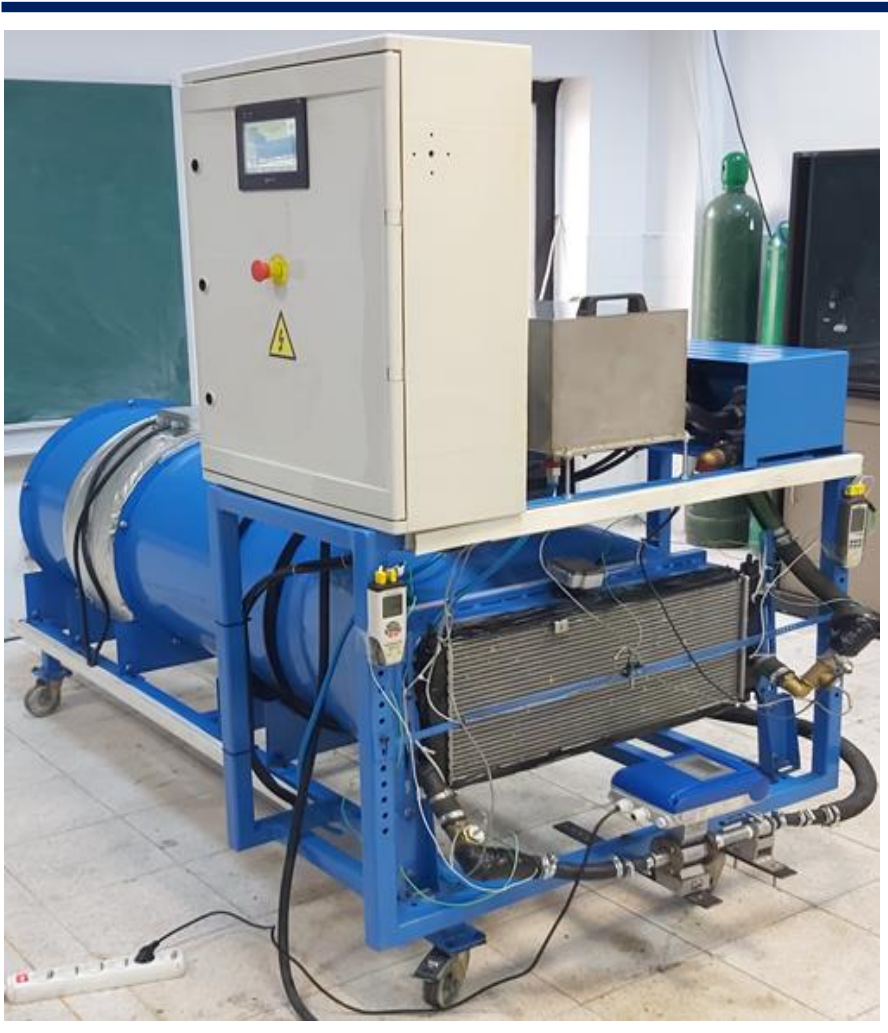

Fig. 2. Photograph of the radiator test system

In the experimental radiator test system, various measuring instruments connected to the PLC were employed. Characteristics of the instruments are shown in Table 1.

The radiator test system was operated through drivers connected to the PLC, and a continuous data flow from the measuring instruments to the PLC was obtained. The desired air temperature at the radiator inlet and air velocity across the radiator as well as the desired coolant volumetric flow rate and coolant temperature at the radiator inlet were entered on the PLC control screen before each test. The PLC was programmed to approach the input values within a tolerance of $1 \%$. After obtaining the required temperature, air velocity and coolant flow rate values within the specified tolerance in about 20 minutes, the PLC completed the test and sent the results to the PLC result screen. The coolant and air outlet temperatures obtained in the test as well as their specified values were indicated on the result screen. The agreements between the results obtained from the PLC screen and the results of manual measurements were checked at certain intervals to make sure that data were acquired properly.

The flat-tube louvered-fin radiator used in the radiator test system belonged to a car with a four-cylinder diesel engine. Geometrical characteristics of the test radiator are reported in Table 2, and its photograph is provided in Fig. 3.

More detailed information about the radiator test system is available in the studies by Keklik and Hoşöz [27, 28], in which the performance of flat-tube and round-tube radiators was compared for water, EG, 50/50 water and heat transfer oil as the coolants. As a further study, the current investigation presents a performance comparison of PG-water mixtures with EG-water mixtures and water in a flat-tube louvered-fin automobile radiator.

Table 2. Geometrical characteristics of the test radiator

\begin{tabular}{c|c}
\hline Core size $(\mathrm{mm})$ & $695 \times 275 \times 28$ \\
\hline Frontal area $\left(\mathrm{m}^{2}\right)$ & 0.191 \\
\hline Tube no. & 24 \\
\hline Tube outside diameter $(\mathrm{mm})$ & $2 \times 26$ \\
\hline Tube thickness $(\mathrm{mm})$ & 0.2 \\
\hline Radiator material & Aluminum \\
\hline Fin thickness $(\mathrm{mm})$ & 0.1 \\
\hline Fin Pitch $(\mathrm{mm})$ & 1.5 \\
\hline Minimum fin height $(\mathrm{mm})$ & 9
\end{tabular}

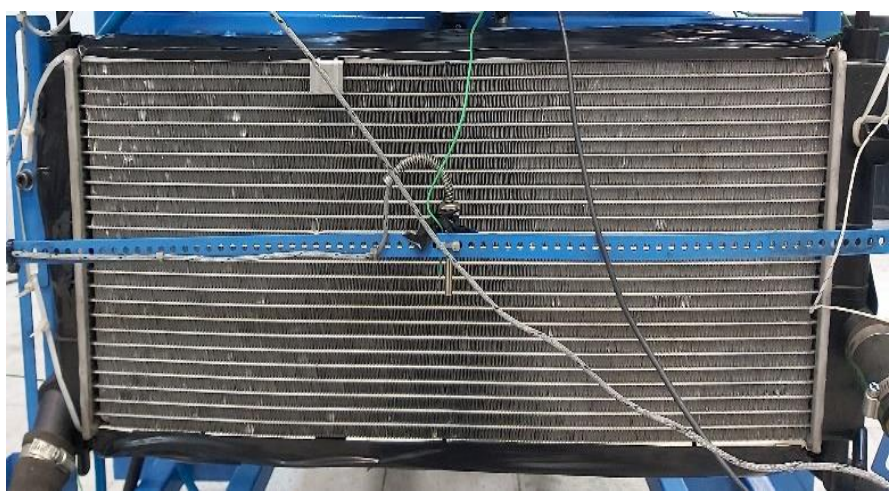

Fig. 3. Flat-tube louvered-fin test radiator

In this study, the performance of the test radiator was experimentally evaluated for five different engine coolants, namely pure water, 30/70 EG/water, 30/70 PG/water, 50/50 EG/water and $50 / 50 \mathrm{PG} /$ water mixtures. The ratios of the coolants specified above are by volume. Various thermophysical properties and freezing temperatures of these coolants at $90{ }^{\circ} \mathrm{C}$ are reported in Table 3.

Tests were carried out by changing the coolant volume flow rate, velocity of the air across the radiator and air temperature at the radiator inlet while the coolant temperature at the radiator inlet was kept constant at $90^{\circ} \mathrm{C}$ in all tests. The air inlet velocity $\left(V_{a}\right)$ was maintained at four different values, namely 1,2,3 and $4 \mathrm{~m} / \mathrm{s}$, and the volumetric flow rate of the coolant $\left(\dot{V}_{c}\right)$ was adjusted to 0.10 , $0.15,0.20$, and $0.25 \mathrm{l} / \mathrm{s}$. Furthermore, the air temperature $\left(T_{a, \text { in }}\right)$ at the radiator inlet was kept at 25,30 and $35^{\circ} \mathrm{C}$. Although 48 tests were performed for each engine coolant, only the results of 28 tests were employed to abridge the findings. Each test was conducted at least five times to minimize the errors and to obtain the averaged steady-state results. Then, totally 1200 tests were conducted with repetitions for five coolants. 
Table 3. Thermophysical properties and freezing points of the tested engine coolants at $90{ }^{\circ} \mathrm{C}[29]$

\begin{tabular}{c|c|c|c|c|c}
\hline Coolant & $\begin{array}{c}\text { Density } \\
\left(\mathbf{k g} / \mathbf{m}^{\mathbf{3}}\right)\end{array}$ & $\begin{array}{c}\text { Specific heat } \\
(\mathbf{k J} / \mathbf{k g ~ K})\end{array}$ & $\begin{array}{c}\text { Thermal } \\
\text { conductivity } \\
(\mathbf{W} / \mathbf{m ~ K})\end{array}$ & $\begin{array}{c}\text { Dynamic viscosity } \\
(\mathbf{k g} / \mathbf{m ~ s})\end{array}$ & $\begin{array}{c}\text { Freezing } \\
\text { point } \\
\left({ }^{\circ} \mathbf{C}\right)\end{array}$ \\
\hline Water & 965.3 & 4.204 & 0.6613 & 0.0003145 & 0 \\
\hline $70 \%$ water / 30\% Ethylene Glycol & 999.3 & 3.873 & 0.5138 & 0.000583 & -16.27 \\
\hline $70 \%$ water / 30\% Propylene Glycol & 980.7 & 4.033 & 0.4978 & 0.000605 & -13.02 \\
\hline $50 \%$ water / 50\% Ethylene Glycol & 1022 & 3.578 & 0.4209 & 0.0008624 & -39.42 \\
\hline $50 \%$ water / 50\% Propylene Glycol & 987.2 & 3.792 & 0.3946 & 0.0009109 & -32.08 \\
\hline
\end{tabular}

The heat rejected by the coolant into the air stream in the radiator is calculated from the following equation:

$Q=\dot{m}_{c}\left(h_{c, i}-h_{c, o}\right)$

In Eq. (1), $\dot{m}_{c}$ stands for the mass flow rate of the coolant while $h_{c, i}$ and $h_{c, o}$ are the enthalpies of the coolant at the radiator inlet and outlet, respectively. The enthalpy values of the coolant were obtained from the EES (Energy Equation Solver) software as functions of the radiator inlet and outlet temperatures, assuming that the pressure of the coolant was equal to the atmospheric pressure [29].

\section{Results and Discussion}

The heat rejected in the test radiator for five different engine coolants is shown in Figs. 4-9 as functions of the test conditions.

The radiator heat rejection rates for the air inlet temperature of $25^{\circ} \mathrm{C}$ were shown in Fig. 4(a) and (b) for the coolant volumetric flow rates of $0.10 \mathrm{l} / \mathrm{s}$ and $0.25 \mathrm{l} / \mathrm{s}$, respectively, as a function of the air speed across the radiator. It is observed that the heat rejection rate enhanced with rising air speed for both coolant flow rates. The highest average heat rejection rate was obtained with water for both coolant flow rates, followed by $30 / 70$ EG/water, 50/50 EG/water, 30/70 PG/water and finally 50/50 $\mathrm{PG} /$ water in decreasing order. As the average of the test results reported in Fig. 4 (a) and (b), 30/70 EG/water, 50/50 EG/water, 30/70 PG/water and 50/50 PG/water yielded 3.83\%, 8.10\%, $9.56 \%$ and $12.42 \%$ lower heat rejection rate, respectively, relative to water. For $25^{\circ} \mathrm{C}$ air inlet temperature, when the coolant flow rate was increased from 0.10 to $0.25 \mathrm{l} / \mathrm{s}$, the heat rejected by water, 30/70 EG/water, 30/70 PG/water, 50/50 EG/water and $50 / 50 \mathrm{PG} /$ water enhanced $23.59 \%, 19.74 \%, 24.32 \%, 20.68 \%$ and $23.25 \%$, respectively. On the other hand, as the average of the test results reported in Fig. 4 (a) and (b), the heat rejected by water, 30/70 EG/water, 30/70 PG/water, 50/50 EG/water and 50/50 PG/water enhanced 45.46\%, 44.35\%, 40.59\%, 44.39\% and $40.47 \%$, respectively, when the air speed was increased from $1 \mathrm{~m} / \mathrm{s}$ to $4 \mathrm{~m} / \mathrm{s}$.
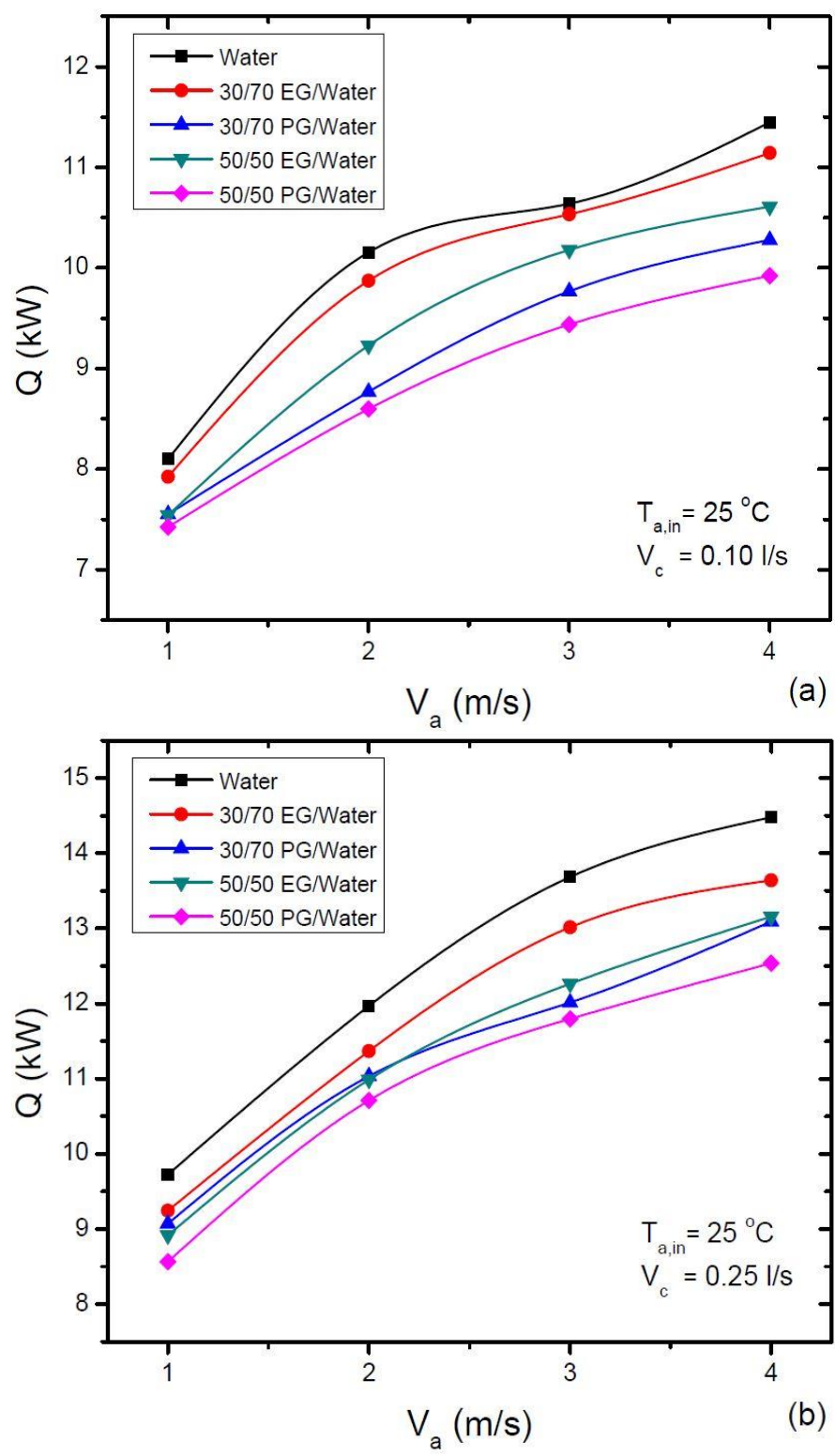

Fig. 4. Variation of the radiator heat rejection rate with the speed of air for $25{ }^{\circ} \mathrm{C}$ air inlet temperature and coolant flow rates of; (a) $\dot{\mathrm{V}}_{c}=0.10$ 1/s, (b) $\dot{\mathrm{V}}_{c}=0.25 \mathrm{l} / \mathrm{s}$ 
The radiator heat rejection rates for the air inlet temperature of $35^{\circ} \mathrm{C}$ were reported in Fig. 5(a) and (b) for the coolant volumetric flow rates of $0.10 \mathrm{l} / \mathrm{s}$ and $0.25 \mathrm{l} / \mathrm{s}$, respectively, as a function of the air speed across the radiator. As observed previously, the heat rejection rate enhanced with rising air speed for both coolant flow rates. The highest average heat rejection rate was obtained with water for both coolant flow rates, followed by $30 / 70 \mathrm{EG} /$ water, 50/50 EG/water, 30/70 PG/water and finally 50/50 PG/water in decreasing order. As the average of the test results indicated in Fig. 5 (a) and (b), 30/70 EG/water, 50/50 EG/water, 30/70 PG/water and 50/50 PG/water resulted in 3.93\%, 8.19\%, 8.19\% and $11.78 \%$ lower heat rejection rate, respectively, in comparison to water.
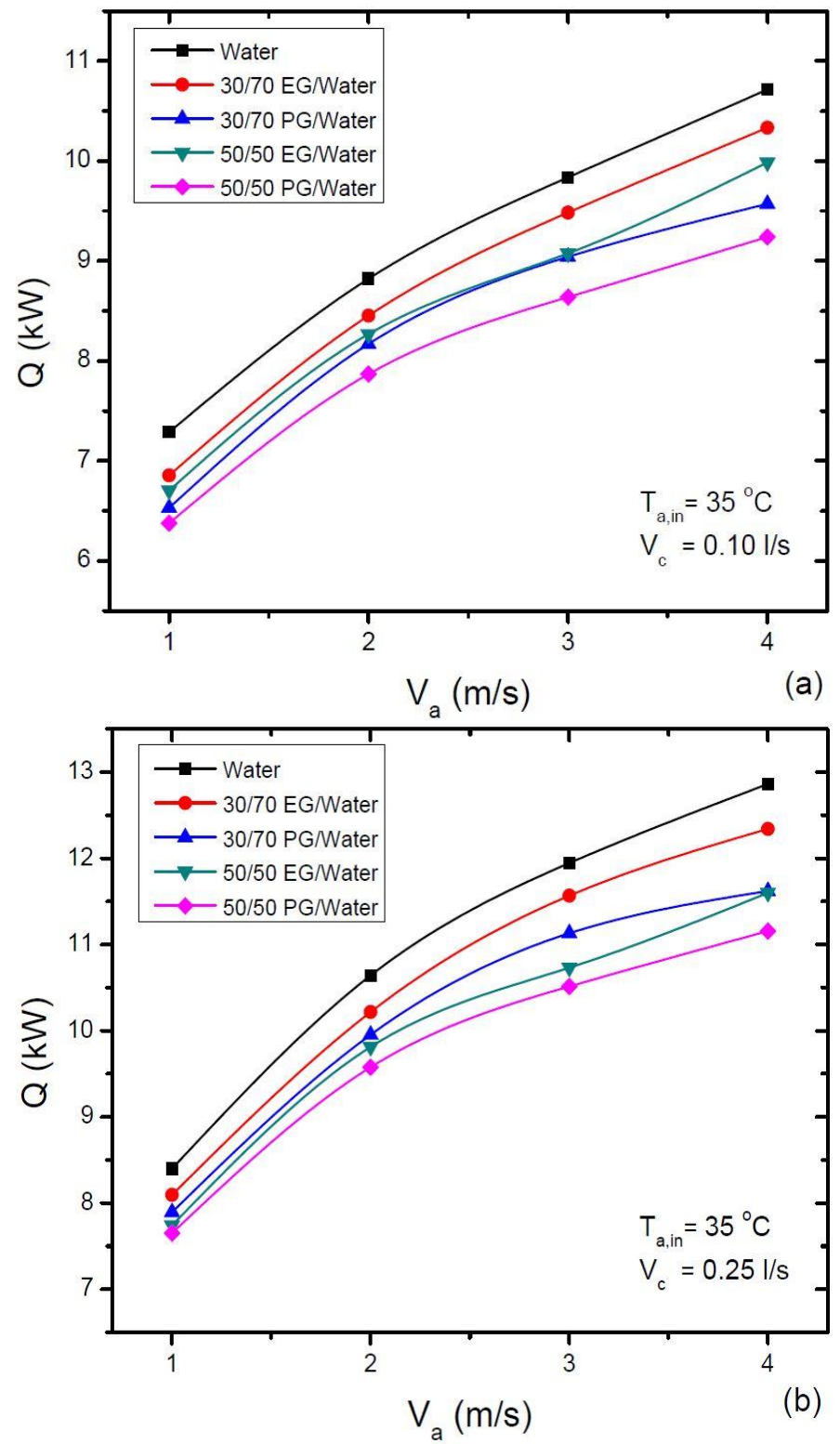

Fig. 5. Variation of the radiator heat rejection rate with the speed of air for $35^{\circ} \mathrm{C}$ air inlet temperature and coolant flow rates of; (a) $\dot{\mathrm{V}}_{c}=0.10$ $1 / \mathrm{s},(\mathrm{b}) \dot{\mathrm{V}}_{c}=0.25 \mathrm{l} / \mathrm{s}$
For $35{ }^{\circ} \mathrm{C}$ air inlet temperature, when the coolant flow rate was increased from 0.10 to $0.25 \mathrm{l} / \mathrm{s}$, the heat rejected by water, 30/70 EG/water, 30/70 PG/water, 50/50 EG/water and 50/50 PG/water enhanced $19.60 \%, 20.19 \%, 21.87 \%, 17.19 \%$ and $21.08 \%$, respectively. Moreover, as the average of the test results reported in Fig. 5 (a) and (b), the heat rejected by water, 30/70 EG/water, 30/70 PG/water, 50/50 EG/water and 50/50 PG/water boosted $50.30 \%, 51.67 \%, 46.90 \%, 49.41 \%$ and $45.39 \%$, respectively, when the air speed was increased from $1 \mathrm{~m} / \mathrm{s}$ to $4 \mathrm{~m} / \mathrm{s}$.
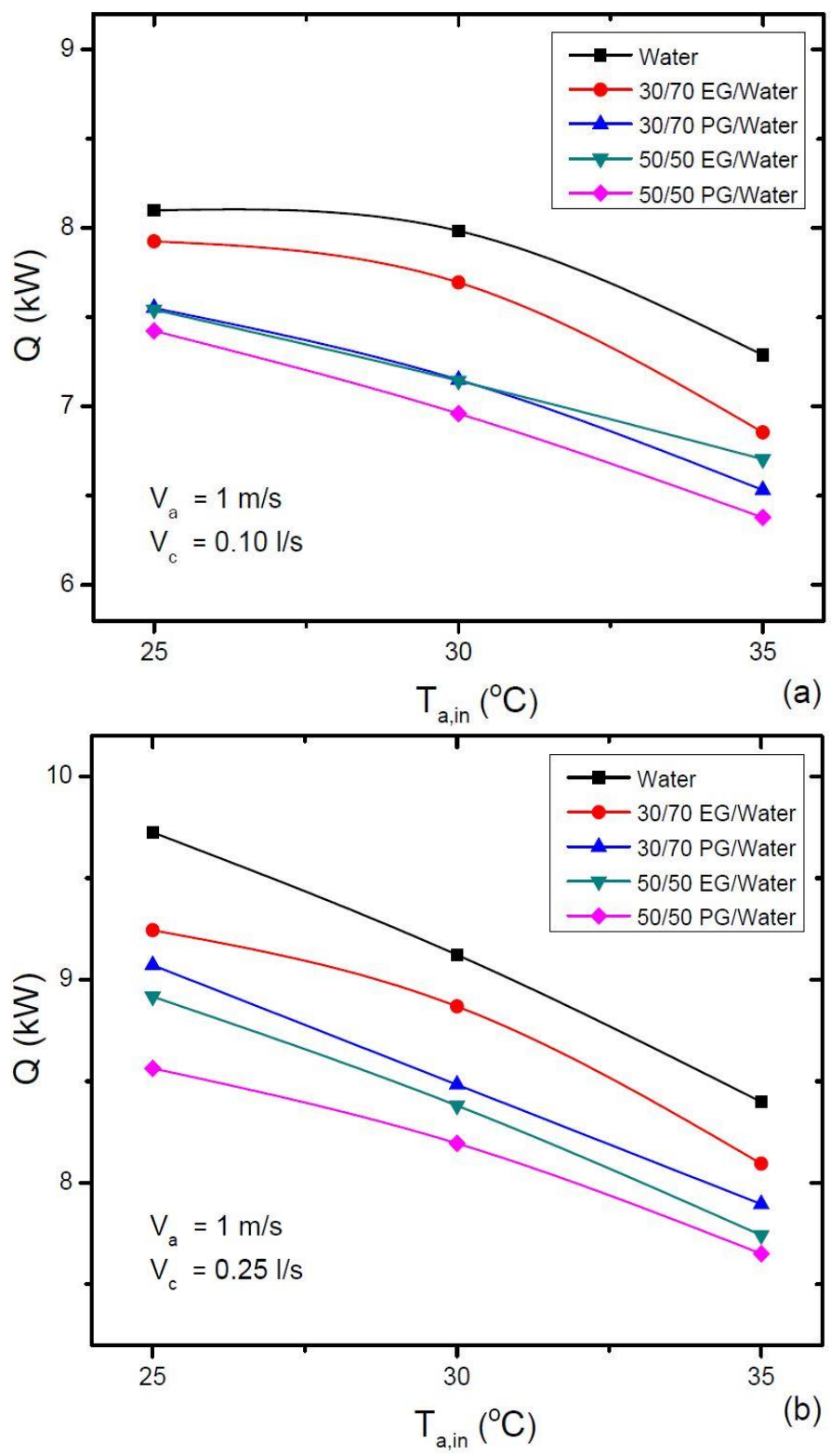

Fig. 6. Variation of the radiator heat rejection rate with air inlet temperature for $1 \mathrm{~m} / \mathrm{s}$ speed air speed and coolant flow rates of;

$$
\text { (a) } \dot{\mathrm{V}}_{c}=0.10 \mathrm{l} / \mathrm{s} \text {, (b) } \dot{\mathrm{V}}_{c}=0.25 \mathrm{l} / \mathrm{s}
$$

The radiator heat rejection rates for the air speed of $1 \mathrm{~m} / \mathrm{s}$ were exhibited in Fig. 6(a) and (b) for the coolant volumetric flow rates of $0.10 \mathrm{l} / \mathrm{s}$ ve $0.25 \mathrm{l} / \mathrm{s}$, respectively, as a function of the air 
temperature at the radiator inlet. It is seen that the heat rejection rate reduced with rising air inlet temperature for both coolant flow rates. The highest average heat rejection rate was yielded by water for both coolant flow rates, followed by 30/70 EG/water, 30/70 PG/water, 50/50 EG/water, and 50/50 PG/water in lessening order. As the average of the test results indicated in Fig. 6(a) and (b), 30/70 EG/water, 30/70 PG/water, 50/50 EG/water, and 50/50 PG/water yielded $3.82 \%, 7.77 \%, 8.27 \%$ and $10.75 \%$ lower heat rejection rate, respectively, relative to water.
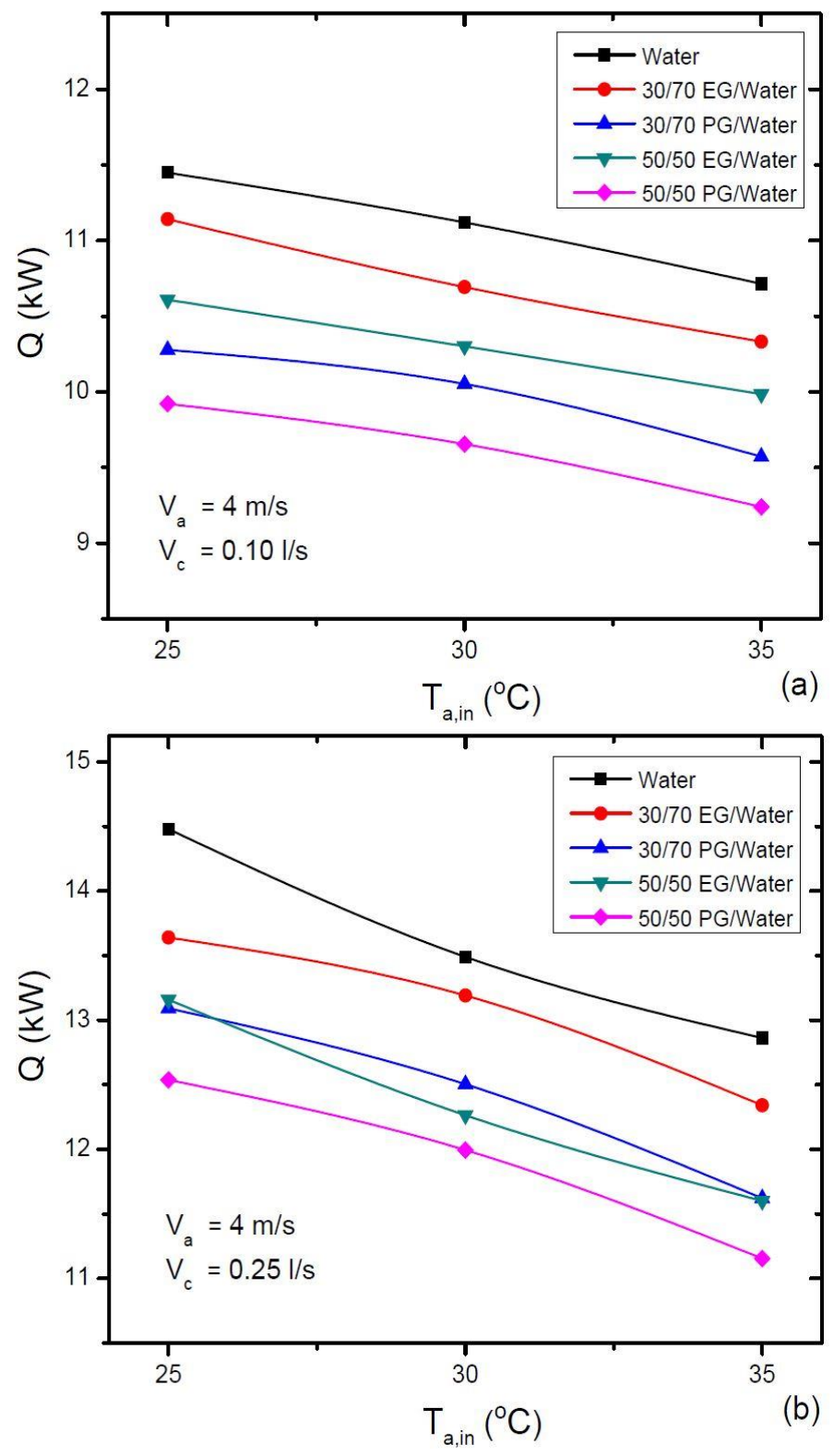

Fig. 7. Variation of the radiator heat rejection rate with air inlet temperature for $4 \mathrm{~m} / \mathrm{s}$ air speed and coolant flow rates of; (a) $\dot{\mathrm{V}}_{c}=0.10 \mathrm{l} / \mathrm{s}$, (b) $\dot{\mathrm{V}}_{c}=0.25 \mathrm{l} / \mathrm{s}$
For $1 \mathrm{~m} / \mathrm{s}$ air speed, when the air inlet temperature was increased from $25{ }^{\circ} \mathrm{C}$ to $35^{\circ} \mathrm{C}$, the heat rejected by water, 30/70 EG/water, 30/70 PG/water, 50/50 EG/water and 50/50 PG/water decreased $11.99 \%, 12.92 \%, 13.21 \%, 12.23 \%$ and $12.25 \%$, respectively, as the average of the test results conducted with both coolant flow rates. Furthermore, when the coolant flow rate was increased from $0.1 \mathrm{l} / \mathrm{s}$ to $0.25 \mathrm{l} / \mathrm{s}$, the heat rejected by water, 30/70 EG/water, 30/70 PG/water, 50/50 EG/water and 50/50 PG/water enhanced $16.58 \%$, $16.60 \%, 19.86 \%, 17.05 \%$ and $17.57 \%$, respectively.

The radiator heat rejection rates for the air speed of $4 \mathrm{~m} / \mathrm{s}$ were reported in Fig. 7(a) and (b) for the coolant volumetric flow rates of $0.10 \mathrm{l} / \mathrm{s}$ and $0.25 \mathrm{l} / \mathrm{s}$, respectively, as a function of the air temperature at the radiator inlet. As observed previously, the heat rejection rate decreased with rising air inlet temperature for both coolant flow rates. The highest average heat rejection rate was obtained with water for both coolant flow rates, followed by $30 / 70$ EG/water, 50/50 EG/water, 30/70 PG/water and 50/50 PG/water in decreasing order. As the average of the test results shown in Fig. 7(a) and (b), 30/70 EG/water, 50/50 EG/water, 30/70 PG/water and $50 / 50 \mathrm{PG} /$ water resulted in $3.74 \%, 8.36 \%, 9.44 \%$ and $12.96 \%$ lower heat rejection rate, respectively, in comparison to water. For $4 \mathrm{~m} / \mathrm{s}$ air speed, when the air inlet temperature was increased from $25^{\circ} \mathrm{C}$ to $35^{\circ} \mathrm{C}$, the heat rejected by water, 30/70 EG/water, 30/70 PG/water, 50/50 EG/water and 50/50 PG/water dropped 9.06\%, $8.50 \%, 9.31 \%, 9.18 \%$ and $9.18 \%$, respectively, as the average of the test results conducted with both coolant flow rates. On the other hand, when the coolant flow rate was increased from $0.1 \mathrm{l} / \mathrm{s}$ to 0.25 $1 / \mathrm{s}$, the heat rejected by water, 30/70 EG/water, 30/70 PG/water, $50 / 50 \mathrm{EG} /$ water and 50/50 PG/water boosted 22.67\%, 21.77\%, $24.46 \%, 19.83 \%$ and $23.84 \%$, respectively.

The radiator heat rejection rates for the air inlet temperature of $25^{\circ} \mathrm{C}$ were shown in Fig. 8(a) and (b) for the air speed of $1 \mathrm{~m} / \mathrm{s}$ and $4 \mathrm{~m} / \mathrm{s}$, respectively, as a function of the coolant volumetric flow rate. It is seen that the heat rejection rate enhanced with rising coolant flow rate for both air speeds. The highest average heat rejection rate was yielded by water for both air speeds, followed by 30/70 EG/water, 50/50 EG/water, 30/70 PG/water and 50/50 $\mathrm{PG} /$ water in decreasing order. As the average of the test results provided in Fig. 8(a) and (b), 30/70 EG/water, 50/50 EG/water 30/70 PG/water and 50/50 PG/water yielded 3.65\%, 7.69\%, 7.95\% and $11.28 \%$ lower heat rejection rate, respectively, relative to water. For $25{ }^{\circ} \mathrm{C}$ air inlet temperature, when the coolant flow rate was increased from 0.10 to $0.25 \mathrm{l} / \mathrm{s}$, the heat rejected by water, 30/70 EG/water, 30/70 PG/water, 50/50 EG/water and 50/50 PG/water increased $23.82 \%, 20.02 \%, 24.31 \%, 21.62 \%$ and $21.65 \%$, respectively, as the average of the test results conducted with both air speeds. Furthermore, when the air speed was increased from $1 \mathrm{~m} / \mathrm{s}$ to $4 \mathrm{~m} / \mathrm{s}$, the heat rejected by water, 30/70 EG/water, 30/70 PG/water, 50/50 EG/water and 50/50 PG/water boosted $44.71 \%, 45.92 \%, 42.66 \%, 46.72 \%$ and $44.73 \%$, respectively. 


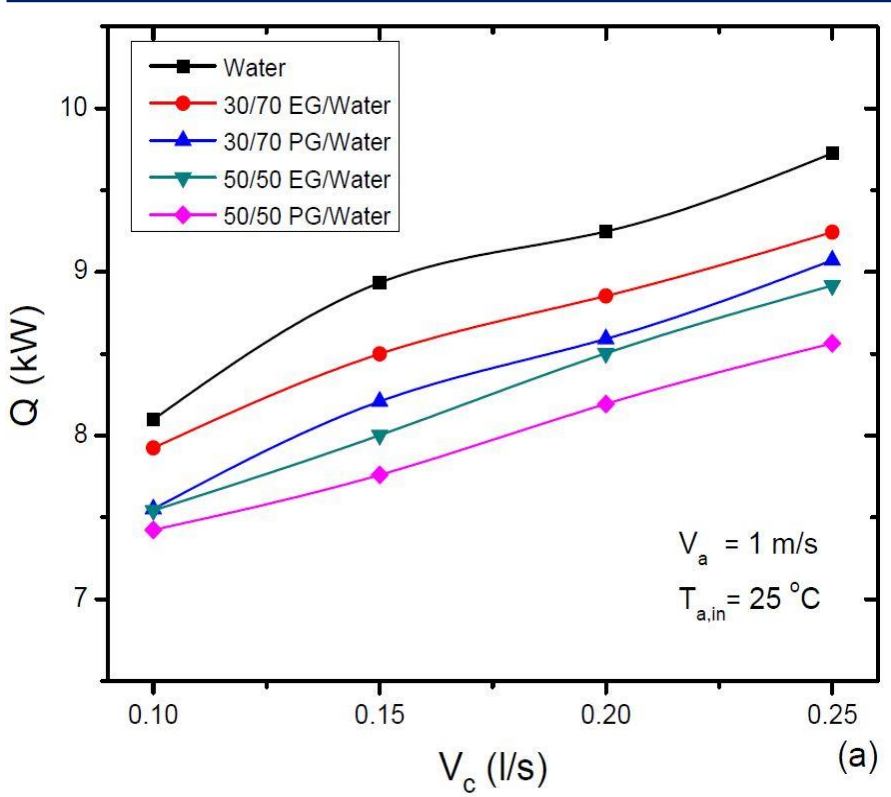

rejected by water, 30/70 EG/water, 30/70 PG/water, 50/50 EG/water and 50/50 PG/water increased 18.09\%, 18.89\%, 21.19\%, $15.89 \%$ and $20.41 \%$, respectively, as the average of the test results conducted with both air speeds. Moreover, when the air speed was increased from $1 \mathrm{~m} / \mathrm{s}$ to $4 \mathrm{~m} / \mathrm{s}$, the heat rejected by water, 30/70 EG/water, 30/70 PG/water, 50/50 EG/water and 50/50 PG/water enhanced 52.46\%, 51.36\%, 47.77\%, 50.28\% and 46.25\%, respectively.
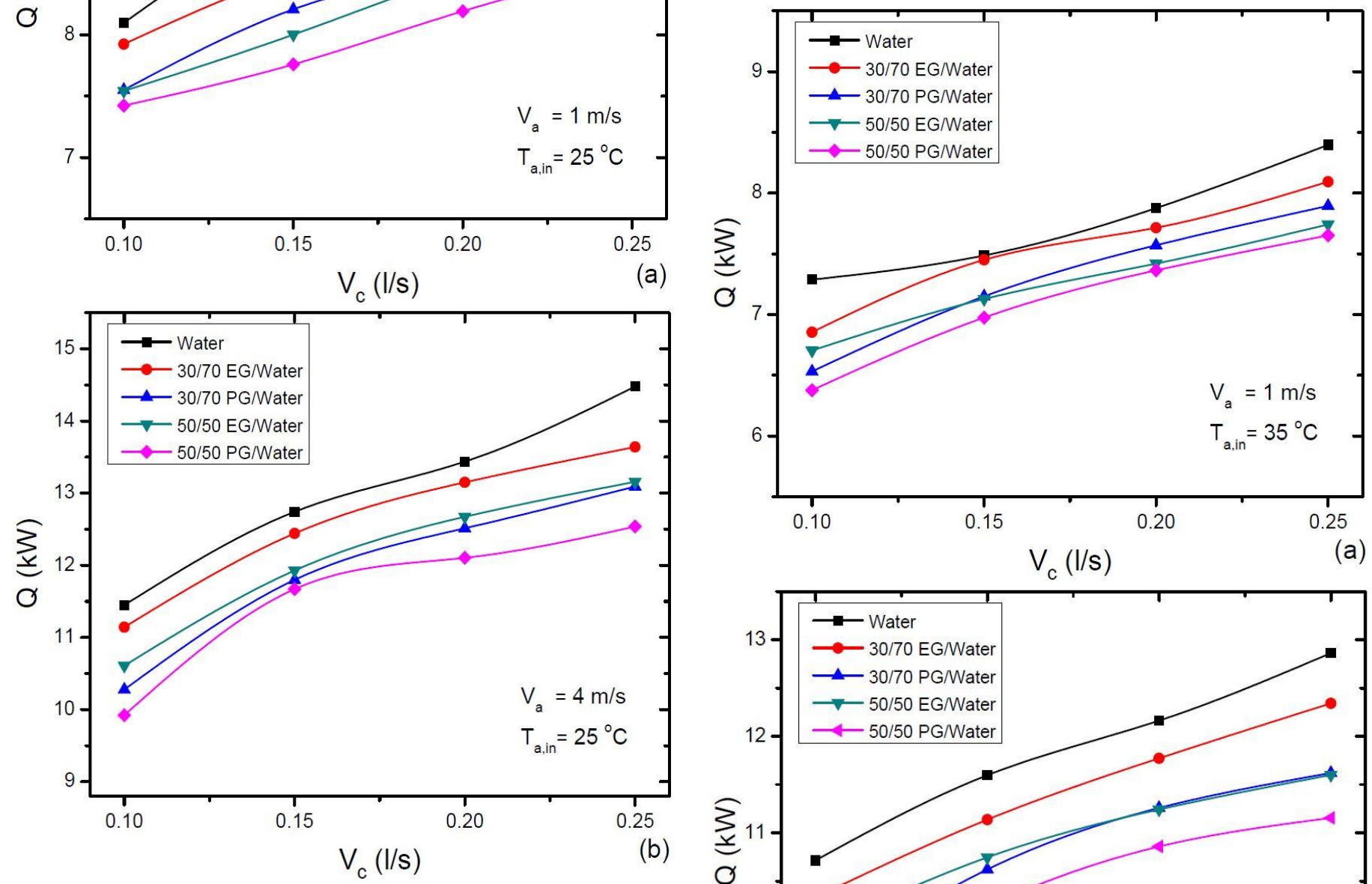

Fig. 8. Variation of the radiator heat rejection rate with the coolant flow rate for $25{ }^{\circ} \mathrm{C}$ air inlet temperature and air speeds of; (a) $V_{a}=1 \mathrm{~m} / \mathrm{s}$, (b) $V_{a}=4 \mathrm{~m} / \mathrm{s}$

The radiator heat rejection rates for the air inlet temperature of $35^{\circ} \mathrm{C}$ were exhibited in Fig. 9(a) and (b) for the air speed of $1 \mathrm{~m} / \mathrm{s}$ and $4 \mathrm{~m} / \mathrm{s}$, respectively, as a function of the coolant volumetric flow rate. As observed previously, the heat rejection rate increased with rising coolant flow rate for both air speeds. The highest average heat rejection rate was obtained with water for both air speeds, followed by 30/70 EG/water, 50/50 EG/water, 30/70 $\mathrm{PG} /$ water and 50/50 PG/water in lessening order. As the average of the test results shown in Fig. 9(a) and (b), 30/70 EG/water, 50/50 $\mathrm{EG} /$ water 30/70 PG/water and 50/50 PG/water resulted in 3.43\%, $7.42 \%, 7.86 \%$ and $10.88 \%$ lower heat rejection rate, respectively, in comparison to water. For $35^{\circ} \mathrm{C}$ air inlet temperature, when the coolant flow rate was rised from $0.10 \mathrm{l} / \mathrm{s}$ to $0.25 \mathrm{l} / \mathrm{s}$, the heat

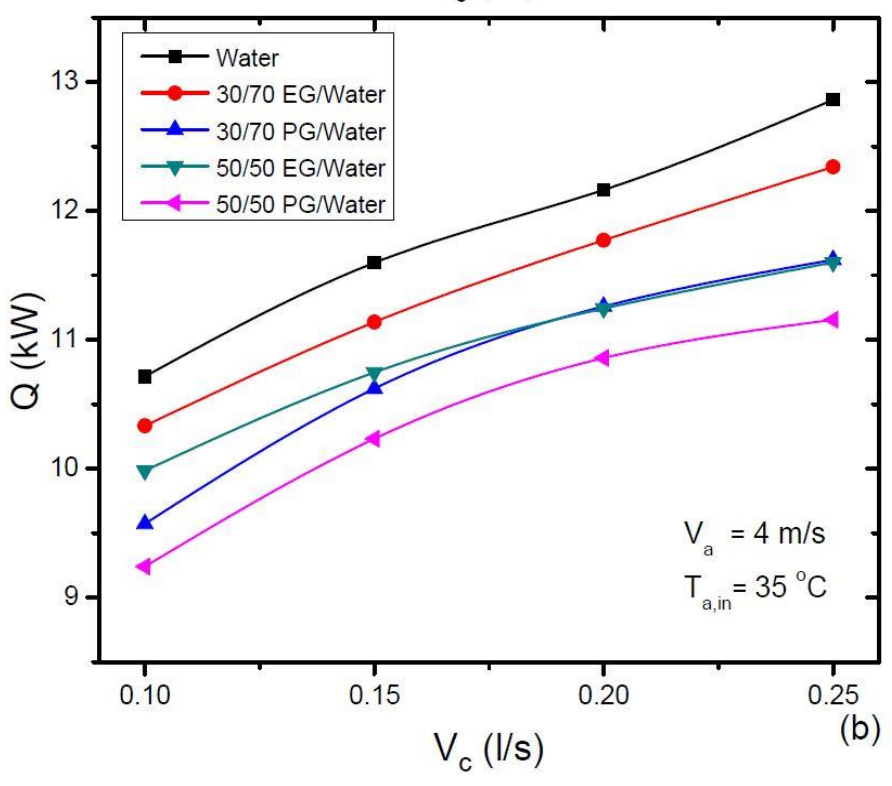

Fig. 9. Variation of the radiator heat rejection rate with the coolant flow rate for $35^{\circ} \mathrm{C}$ air inlet temperature and air speeds of; (a) $\mathrm{V}_{\mathrm{a}}=1 \mathrm{~m} / \mathrm{s}$, (b)

$$
\mathrm{V}_{\mathrm{a}}=4 \mathrm{~m} / \mathrm{s}
$$

\section{Conclusions}

In this study, thermal performances of five different engine coolants, namely water, 30/70 EG/water, 50/50 EG/water, 30/70 $\mathrm{PG} /$ water and 50/50 PG/water were experimentally evaluated by 
using a radiator test system employing a flat-tube louvered-fin automobile radiator. Thanks to its PLC controlled components, the experimental system has the capability of changing the coolant volumetric flow rate, coolant inlet temperature, air speed and air inlet temperature in a wide range, thus providing the required test conditions. In the tests, the coolant flow rate was varied between $0.10 \mathrm{l} / \mathrm{s}$ and $0.25 \mathrm{l} / \mathrm{s}$, the air speed was changed between $1 \mathrm{~m} / \mathrm{s}$ and $4 \mathrm{~m} / \mathrm{s}$ and the air inlet temperature was varied between $25{ }^{\circ} \mathrm{C}$ and $35{ }^{\circ} \mathrm{C}$, while the coolant inlet temperature was kept constant at $90{ }^{\circ} \mathrm{C}$ in all tests. The thermal performance of the radiator was evaluated using the measurement data acquired after the steady state had been reached. Based on experimental evidence, the following conclusions were obtained.

- As the average of all tests, the highest heat rejection rate was obtained with water, which followed by 30/70 EG/water, 50/50 EG/water, 30/70 PG/water and 50/50 PG/water in reducing order.

- As the average of all tests, 30/70 EG/water, 50/50 EG/water 30/70 PG/water and 50/50 PG/water yielded 3.50\%, 7.89\%, $8.28 \%$ and $11.46 \%$ lower heat rejection rate relative to water.

- When the air speed was augmented from $1 \mathrm{~m} / \mathrm{s}$ to $4 \mathrm{~m} / \mathrm{s}$, as the average of all related test results, the heat rejected by water, 30/70 EG/water, 30/70 PG/water, 50/50 EG/water and 50/50 PG/water boosted $47.40 \%, 47.59 \%, 44.89 \%, 47.78 \%$ and $44.93 \%$, respectively.

- When the air inlet temperature was increased from $25^{\circ} \mathrm{C}$ to $35^{\circ} \mathrm{C}$, as the average of all related test results, the heat rejected by water, 30/70 EG/water, 30/70 PG/water, 50/50 EG/water and 50/50 PG/water decreased $11.09 \%, 10.99 \%$, $9.92 \%, 10.91 \%$ and $10.33 \%$, respectively.

- When the coolant flow rate was augmented from $0.1 \mathrm{l} / \mathrm{s}$ to $0.25 \mathrm{l} / \mathrm{s}$, as the average of related test results, the heat rejected by water, 30/70 EG/water, 30/70 PG/water, 50/50 EG/water and 50/50 PG/water boosted $21.03 \%, 19.96 \%$, $22.92 \%, 18.88 \%$ and $22.08 \%$, respectively.

- The parameter having the greatest impact on the radiator thermal performance was the air speed, followed by the coolant flow rate and air inlet temperature in lessening order.

- Although 30/70 PG/water coolant usually yielded about the same average heat transfer performance with 50/50 EG/water coolant, which is commonly used coolant in internal combustion engines, it sometimes exhibited even better performance than 50/50 EG/water coolant.

Although the results show that water is the best coolant in terms of thermal performance, evaluations made by considering the corrosion effect as well as the desired freezing and boiling points of the coolant suggest the use of water-glycol mixtures. As determined in this study, PG is highly competitive with EG in terms of thermal performance. Furthermore, it is less toxic, cheap, easily producible, and decomposable in comparison to EG. Therefore, it can be used an alternative to PG in applications where a more environmentally friendly coolant is desired.

\section{Nomenclature}

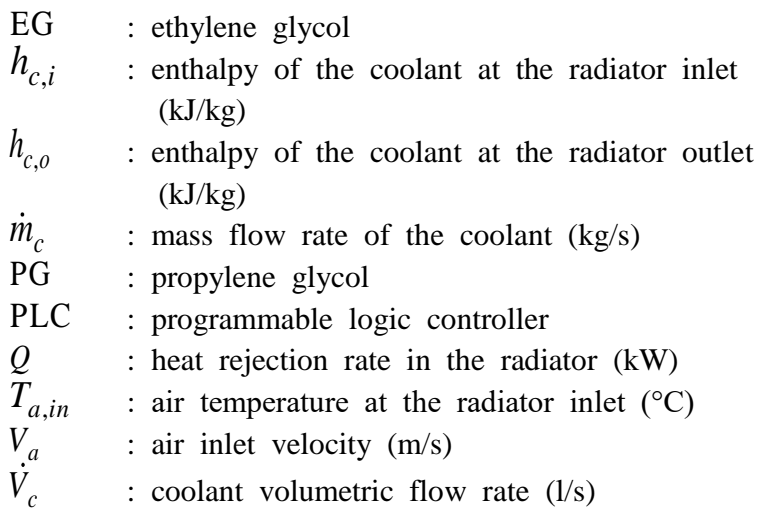

\section{Conflict of Interest Statement}

The authors declare that there is no conflict of interest.

\section{CRediT Author Statement}

Ahmet Gündem: Conceptualization, Data Curation, Writing-original draft,

Murat Hoşöz: Conceptualization, Writing-original draft, supervision,

Erkan Keklik: Experimental Design, validation.

\section{References}

[1] Rajput RK. Internal combustion engine. 2nd ed. India: Laxmi Publications Ltd.; 2007.

[2] Heywood JB. Internal combustion engine fundamentals. New York: Mc-Graw-Hill, Inc.; 1998.

[3] Subhedar DG, Ramani BM, Gupta A. Experimental investigation of heat transfer potential of $\mathrm{Al}_{2} \mathrm{O}_{3}$ /water-mono ethylene glycol nanofluids as a car radiator coolant. Case Stud in Therm Eng. 2018;11:26-34.

[4] Pérez-Tavernier J, Vallejo JP, Cabaleiro D, Fernández-Seara J, Lugo L. Heat transfer performance of a nano-enhanced propylene glycol:water mixture. Int J of Therm Sci. 2019;139:413-423.

[5] Sahoo RR, Ghosh P, Sarkar J. Energy and exergy comparisons of water based optimum brines as coolants for rectangular fin automotive radiator. Int J of Heat and Mass Transf. 2017;105:690-696.

[6] Gollin M, Bjork D. Comparative performance of ethylene glycol/water and propylene glycol/water coolants in automobile radiators. In: SAE Technical Papers. 1996.

[7] Soylu S, Atmaca İ, Asiltürk M, Doğan A. Improving heat transfer performance of an automobile radiator using $\mathrm{Cu} \mathrm{Ag}$ doped $\mathrm{TiO}_{2}$ based nanofluids. Appl Therm Eng. 2019;157.

[8] Kumar A, Hassan MA, Chand P. Heat transport in nanofluid coolant car radiator with louvered fins. Powder Technol. 2020;376:631-642.

[9] Rai P, Kumar A, Yadav Anshul. Experimental investigation of heat transfer augmentation in automobile radiator using magnesium oxide/distilled water-ethylene glycol based nanofluid. Materials Today: Proceedings. 2020;24:1525-32.

[10]Juniour LCC, Nogueira É. Influence of the coolant flow containing silver nanoparticles $(\mathrm{Ag})$ from an aqueous solution based on ethylene 
glycol (EG50\%) on the thermal-hydraulic performance of an automotive radiator. World J of Nano Sci and Eng. 2020;10:10-26.

[11]Sahoo RR, Ganosh P, Sarkar J. Performance comparison of various coolants for louvered fin tube automotive radiator. Therm Sci 2017;21(6B):2871-81.

[12]Habibian SH, Abolmaali AM, Afshin H. Numerical investigation of the effects of fin shape, antifreeze and nanoparticles on the performance of compact finned-tube heat exchangers for automobile radiator. Appl Therm Eng. 2018;133:248-260.

[13]Scott LF, Weir TW. Comparing the Performance of ethylene glycol and propylene glycol coolants in heavy duty vehicles. In: SAE Technical Papers. 1996.

[14]Juger JJ, Crook RF. Heat transfer performance of propylene glycol versus ethylene glycol coolant solutions in laboratory testing. In: SAE Technical Papers. 1999.

[15]Greaney JP, Brunner K, Coburn CR. Low temperature performance of propylene glycol engine coolant. SAE Transaction. 1995;104:80311.

[16]Greaney JP, Cozzone GE. Comparative performance of aqueous propylene glycol and aqueous ethylene glycol coolants. In: SAE Technical Papers. 1999.

[17]Tijani AS, Sudirman AS. Thermos-physical properties and heat transfer characteristics of water/anti-freezing and $\mathrm{Al}_{2} \mathrm{O}_{3} / \mathrm{CuO}$ based nanofluid as a coolant for car radiator. Int $\mathrm{J}$ of Heat and Mass Transf. 2018;18:48-57.

[18]Goudarzi K, Jamali $\mathrm{H}$. Heat transfer enhancement of $\mathrm{Al}_{2} \mathrm{O}_{3} / \mathrm{EG}$ in a car radiator with wire coil inserts. Appl Therm Eng. 2017;118:510 17.

[19]Elsaid AM. Experimental study on the heat transfer performance and friction factor characteristics of $\mathrm{Co}_{3} \mathrm{O}_{4}$ and $\mathrm{Al}_{2} \mathrm{O}_{3}$ based $\mathrm{H}_{2} \mathrm{O} /\left(\mathrm{CH}_{2} \mathrm{OH}\right)_{2}$ nanofluids in a vehicle engine radiator. Int Commun Heat and Mass Transf. 2019;108.

[20]Ahmed SA, Ozkaymak M, Sözen A, Menlik T, Fahed A. Improving car radiator performance by using $\mathrm{TiO}_{2}$-water nanofluid. Int J Eng Sci Technol. 2018; 67(11):22-38.

[21]Zhou X, Wang Y, Zheng K, Huang H. Comparison of heat transfer performance of $\mathrm{ZnO}-\mathrm{PG}, \alpha-\mathrm{Al}_{2} \mathrm{O}_{3}-\mathrm{PG}$ and $\gamma-\mathrm{Al}_{2} \mathrm{O}_{3}-\mathrm{PG}$ nanofluids in car radiator. Nanomater Nanotechnol. 2019;9:1-12.

[22] Salamon V, Kumar DS, Thirumalini S. Experimental investigation of heat transfer characteristics of automobile radiator using $\mathrm{TiO}_{2}$ nanofluid coolant. IOP Conference Series. Mater Sci Eng 2017;225.

[23]Jagadishwar K, Sudhakar Babu S. Performance investigation of water and propylene glycol mixture based nano-fluids on automotive radiator for enhancement of heat transfer. Int J Mech Eng Technol 2017;8(7):822-33.

[24]Elsebay M, Elbadawy I, Shedid MH, Fatouh M. Numerical resizing study of $\mathrm{Al}_{2} \mathrm{O}_{3}$ and $\mathrm{CuO}$ nanofluids in the flat tubes of a radiator. Appl Math. Model. 2016;40:6437-50.

[25]Ali HM, Ali H, Liaquat H, Maqsood HTB, Nadir MA. Experimental investigation of convective heat transfer augmentation for car radiator using ZnO-water nanofluids. Energy. 2015;84:317-24.

[26]Ramalingham S, Dhairiyasamy R, Govindasamy M, Muthaiah RJV. Consequence of nanoparticles size on heat transfer characteristics of a radiator. Powder Technol. 2020;367:213-24.
[27]Keklik E, Hoşöz M. Experimental heat transfer performance of a louvered-fin and flat-tube automotive radiator for various engine coolants, International Conference on Innovative Engineering Applications, 20-22 September 2018, Sivas, Turkey, 278-285.

[28]Keklik E, Hoşöz M. Comparison of the experimental performance of round and flat tube automobile radiators for various coolants, $\mathrm{J}$ of Polytec 2020;23(4): 1121-30.

[29]Klein SA. EES: Engineering Equation Solver. Version 10.167. FChart Software. 